\title{
The roles of photorespiration and alternative electron acceptors in the responses of photosynthesis to elevated temperatures in cowpea
}

\author{
Isaac Osei-Bonsu ${ }^{1}$, Alan McClain², Berkley Walker ${ }^{1}$, Thomas Sharkey², and David M. \\ Kramer $^{1}$ \\ ${ }^{1}$ MSU-DOE Plant Research Laboratory \\ ${ }^{2}$ Michigan State University
}

July 21, 2020

\begin{abstract}
We explored the effects, on photosynthesis in cowpea (Vigna unguiculata), of high temperature and light — environmental stresses that often co-occur under field conditions. We observed contrasting responses in the light and carbon assimilatory reactions, whereby in high temperature, the light reactions were stimulated while CO2 assimilation was substantially reduced. There were two striking observations. First, the primary quinone acceptor (QA), a measure of the regulatory balance of the light reactions, became more oxidized with increasing temperature, suggesting increased electron sink capacity, despite the reduced $\mathrm{CO} 2$ fixation. Second, a strong, O2-dependent inactivation of assimilation capacity, consistent with down-regulation of rubisco under these conditions, a phenomenon that has not been previously reported. The dependence of these effects on CO2, $\mathrm{O} 2$ and light led us to conclude that both photorespiration and an alternative electron acceptor, supported increased electron flow, and thus provided photoprotection, under these conditions. Further experiments showed that the increased electron flow was maintained by rapid rates of PSII repair, particularly at combined high light and temperature. Overall, the results suggest that photodamage to the light reactions can be avoided under high light and temperatures by increasing electron sink strength, even when assimilation is strongly suppressed.
\end{abstract}

\section{Keywords}

Photorespiration, high temperature, high-light, alternative electron acceptors, cowpea, , heat stress, net $\mathrm{CO}_{2}$ assimilation, PSII efficiency

\section{INTRODUCTION}

Heat stress is a major environmental challenge for plants, and it is well established that, in a wide range of species, high temperature (HT) stress can lead to declines in photosynthesis (Cui, Li, Fan, Xu, \& Zhang, 2006; Panigrahi, Pradhan, Panda, Panda, \& Joshi, 2016; Tan, Meng, Brestic, Olsovska, \& Yang, 2011; Wise, Olson, Schrader, \& Sharkey, 2004). The impact of HT stress on photosynthesis is dependent on factors such as leaf developmental age, duration and previous history of exposure (Hasanuzzaman, Nahar, Alam, Roychowdhury, \& Fujita, 2013), as well as other environmental factors, especially high-light (HL) stress, which often co-occur with and can be compounded by HT (Weis, 1982).

While light energy is essential for photosynthesis, excessive light can cause detrimental effects on photosynthesis, a phenomenon known as photoinhibition or photodamage (Aro, Virgin, \& Andersson, 1993; Long, Humphries, \& Falkowski, 1994; Nishiyama \& Murata, 2014). HL stress causes reductions in photosynthesis, especially under rapidly fluctuating environmental conditions, which ultimately results in loss of crop productivity (Slattery, Walker, Weber, \& Ort, 2018). Plants have evolved various mechanisms to deal with excessive light and prevent damage, including changes in leaf orientation (Gamon \& Pearcy, 1989; Pastenes, 
Pimentel, \& Lillo, 2005), chloroplast movement (Suetsugu, Higa, Gotoh, \& Wada, 2016; Wada, 2013) and non-photochemical quenching (NPQ) processes that dissipate excitation energy (Ruban, 2016; Stefanov \& Terashima, 2008). There are several forms of NPQ, including the rapidly reversible "energy dependent" quenching $\left(q_{\mathrm{E}}\right)$, which is activated by acidification of the thylakoid lumen (Avenson, Cruz, \& Kramer, 2004; Li et al., 2004), and more slowly-reversible forms including $q_{\mathrm{I}}$, which is caused by accumulation of inactive (photodamaged) photosystem II (PSII) centers (Krause, Somersalo, Zumbusch, Weyers, \& Laasch, 1990) and state transitions $(q \mathrm{~T})$ that can divert PSII-associated light harvesting complexes (LHCs) to PSI. Depending on its redox state, PSI can either use light energy from these LHCs for PSI photochemistry, or dissipate it as heat (Butler, 1978; Joly \& Carpentier, 2007).

The importance of light for thermotolerance of photosynthesis has been noted in previous work (Buchner, Stoll, Karadar, Kranner, \& Neuner, 2015; Havaux, Greppin, \& Strasser, 1991; Weis, 1982). Although, there have been several studies that show that HL combined with HT accentuates photoinhibition (e.g. Chen et al., 2017; Havaux, 1992; Lu et al., 2017), there are also reports, for instance in tomatoes, where combined moderate HT and HL improved tolerance of photosynthesis compared to either treatment alone (Gerganova, Popova, Stanoeva, \& Velitchkova, 2016). However, since different species have different light intensity requirements (e.g shade vs. sun adapted plants, (Hemming, 2011; C. H. Lin, McGraw, George, \& Garret, 1999)), it is very likely that responses to combinations of HT and HL stress are dependent on genotype, species or acclimation during development. Nevertheless, several components of the responses may be conserved among species.

During photosynthesis, light energy captured by the light harvesting complex is used to drive electrons by linear electron flow (LEF) to store reducing power in $\mathrm{NADPH} / \mathrm{O}_{2}$ and phosphorylation potential in $\mathrm{ATP} / \mathrm{ADP}+\mathrm{Pi}$, which together drive the carbon assimilation reactions in the Calvin-Benson-Bassham (CBB) cycle and other cellular processes. In principle, both the light reactions and CBB cycle may be affected by HT. For example, it is well-established that HT decreases the specificity of rubisco and solubility of $\mathrm{CO}_{2}$ relative to $\mathrm{O}_{2}$ (Brooks \& Farquhar, 1985; Galmés, Hermida-Carrera, Laanisto, \& Niinemets, 2016), thus increasing "photorespiratory pressure" or rates of photorespiration faster than the rate of rubisco carboxylation (Schuster \& Monson, 1990).

In addition to this shift from assimilation to photorespiration, moderately high temperatures $\left(35-40{ }^{\circ} \mathrm{C}\right)$ decrease rubisco activity, which can be attributed to the loss of rubisco activase activity, leading to progressive deactivation of rubisco by accumulation of inhibitory products such as sugar phosphates (Crafts-Brandner \& Salvucci, 2000; Salvucci \& Crafts-Brandner, 2004). While these studies suggest that reduction in rubisco activity is a primary deleterious effect of HT stress, it has also been proposed (Sharkey, 2005) that this effect constitutes an adaptive mechanism possibly to avoid situations where the damage by toxic products of photorespiration outweighs the advantage of higher carbon fixation rates.

A rubisco activase feedback mechanism of this type could allow for "safe" downregulation of assimilation. However, this mode of regulation should decrease the availability of sinks for the products of the light reactions. Without coordinated downregulation of the light reactions, this mode of regulation could result in the accumulation of reactive intermediates and subsequent photodamage. Indeed, it has been proposed that high rates of photorespiration under environmental stresses can serve a photoprotective role by maintaining electron acceptor sinks (Huang, Hu, \& Zhang, 2015; Voss, Sunil, Scheibe, \& Raghavendra, 2013). However, if rubisco is completely deactivated, rates of photorespiration would also be decreased. Thus, many times HT results in decreases in assimilation that are not fully accounted for by increased photorespiration (Sharkey, 2005), suggesting that feedback systems must operate to coordinate the capture of light in response to these changes in assimilation, as suggested by observations that HT induced decreases in assimilation in wheat were not accompanied by increased PSII photodamage (Kalituho, Pshybytko, Kabashnikova, \& Jahns, 2003).

The light and assimilatory reactions are tightly co-regulated to balance the needs for efficient energy capture, while balancing energy storage into ATP and NADPH to meet the needs of downstream metabolic reactions and prevent the accumulation of reactive intermediates that can lead to photodamage (Kramer \& Evans, 2011; (Walker, Kramer, Fisher, \& Fu, 2020). The thylakoid proton motive force (pmf ) plays a central role 
in this co-regulatory network (Avenson et al., 2005; Kanazawa \& Kramer, 2002). The $\Delta \mathrm{pH}$ component of pmf causes acidification of the lumen, which activates $q_{\mathrm{E}}$ (Li, Muller-Moule, Gilmore, \& Niyogi, 2002; Ruban, Johnson, \& Duffy, 2012) and controls electron flow at the level of the cytochrome ${ }_{6} f$ complex, in a process known as "photosynthetic control" (Tikhonov, 2014). The pmf and its effects on downregulation are sensitive to processes that alter the influx of protons such as LEF, cyclic electron flow (CEF) and the conductivity of the thylakoid membrane to proton efflux $\left(\mathrm{g} \mathrm{H}^{+}\right)$. The latter is governed mainly by the chloroplast ATP synthase, and the partitioning of pmf into its two components, $\Delta \psi$ and $\Delta \mathrm{pH}$. For example, decreasing $\mathrm{CO}_{2}$ level slows assimilation and thus decreases LEF and the flux of protons into the lumen. However, ATP synthase also slows, so despite the fact that proton influx is slowed, the thylakoid builds up a larger pmf, leading to activation of $q$ Eand increased photosynthetic control (Kanazawa \& Kramer, 2002). Moderate HT has been shown to modulate this co-regulatory network in tobacco by altering $g_{\mathrm{H}}^{+}$, the rates of violaxanthin de-epoxidase (VDE) and zeaxanthin epoxidase (ZE) and the partitioning of pmf into $\Delta \psi$ and $\Delta \mathrm{pH}$ (Zhang, Kramer, Cruz, Struck, \& Sharkey, 2011), but it is unclear how HL interacts with these regulatory responses.

In this study, we focused on the effect of light on responses of photosynthesis to HT in cowpea (Vigna unguiculata) seedlings having leaves of different maturity, with the aim of determining the relative effects on assimilation and light reactions and their co-regulation. We focused on cowpea because it is an agriculturally important crop that serves as an essential source of livelihood and nutrition for many in developing countries, many of which have hot climates. Characterized by quick growth and broad leaves, it is ideal for studying the interaction between HL and HT since it exhibits considerable genetic variation in tolerance to these traits (Ehlers \& Hall, 1996, 1998).

Our data shows that in low light (LL), $\mathrm{HT}$ caused substantial decreases in $\mathrm{CO}_{2}$ assimilation and PSII activity, while $\mathrm{HT}$ in combination with $\mathrm{HL}$ led to a stimulation of PSII activity, but decreases in $\mathrm{CO}_{2}$ assimilation compared to growth temperature (GT). Further experiments revealed differences in the rates of PSII photodamage between GT $+\mathrm{HL}$ and $\mathrm{HT}+\mathrm{HL}$, whereas PSII activity was not enhanced in $\mathrm{HT}+\mathrm{HL}$ under non-photorespiratory conditions, suggesting photorespiration and other alternative electron acceptors to be essential for tolerance of PSII to HT+HL stress.

\section{MATERIALS AND METHODS}

Plant materials and growth conditions

Two cowpea genotypes, Yacine and 58-77, generously provided by Drs Philip Roberts and Bao-Huhyn Lam, from University of California, Riverside were used for all experiments. These lines exhibited apparent tolerance and sensitivity respectively to HL stress. One seed was sown in $1 \mathrm{~L}$ pot filled with Suremix potting medium (Michigan Grower Products Inc, USA) and watered with half-strength Hoagland's nutrient solution. Plants were staged in a reach-in growth chamber with the following conditions: $\mathrm{RH}, 50 \%$; temperature, 30/20 ${ }^{\circ} \mathrm{C}$ day/night; light intensity, up to $400 \mu \mathrm{mol} \mathrm{m} \mathrm{m}^{-2} \mathrm{~s}^{-1}$ and photoperiod of 10/14 h light/dark. Seedlings were moved to a Dynamic Environment Photosynthesis Imager (DEPI) chamber (Cruz et al., 2016) for treatments 3-4 d or 12-14 d after germination for the young leaves or mature leaves respectively for treatments and assessment of photosynthetic parameters. Where necessary, older plants were used but leaves of similar maturity were used for all measurements. The relative humidity $(\mathrm{RH})$ varied from $20-40 \%$ for the HT treatments whereas it was kept at $50 \%$ for the Control treatment.

High temperature and high-light treatments

Various HT and HL treatments are described in detail within the corresponding figure descriptions. Briefly, HT treatments were imposed by heating the air temperature in the chamber using the native environmental control embedded in the growth chamber to $45^{\circ} \mathrm{C}$. For the temperature response curves, the temperature was changed by $5{ }^{\circ} \mathrm{C}$ every $2 \mathrm{~h}$ (starting from GT of $30^{\circ} \mathrm{C}$ ) but measurements were made after exposure for at least $1 \mathrm{~h}$. Illumination in the DEPI chamber was provided by LED lights with wavelength in photosynthetically active radiation (PAR) range. The light intensity treatments consisted of low light (LL $-300 \mu \mathrm{mol} \mathrm{m}^{-2} \mathrm{~s}^{-1}$ ) and high-light (HL - either 1000 or $1500 \mu \mathrm{mol} \mathrm{m}^{-2} \mathrm{~s}^{-1}$ ). 
Chlorophyll fluorescence and absorbance change measurements

the maximal PSII efficiency $\left(\mathrm{F}_{\mathrm{V}} / \mathrm{F}_{\mathrm{M}}\right)$, plants were dark adapted for 20 min before measurements were made. Most chlorophyll fluorescence measurements were made using either the MultispeQ V1 linked to the PhotosynQ platform [www.photosynq.org , (Kuhlgert et al., 2016)] or the image-based DEPI chamber (Cruz et al., 2016). Some fluorescence measurements were also performed simultaneously with gas exchange measurements using the LI-COR 6800 (Lincoln, Nebraska, USA).

The electrochromic shift was assessed simultaneously with chlorophyll fluorescence measurements using the MultispeQ V1, thus enabling us to connect PSII function with downstream reactions such as the ATP synthase activity. The thylakoid conductivity to protons $\left(\mathrm{g} \mathrm{H}^{+}\right)$was determined by the dark interval relaxation kinetics (DIRK) of the electrochromic shift (ECS) at $520 \mathrm{~nm}$ (Thomas J Avenson, Cruz, Kanazawa, \& Kramer, 2005; Takizawa, Cruz, Kanazawa, \& Kramer, 2007) and was utilized as a measure for the chloroplast ATP synthase activity. The proton motive force ( $\mathrm{pmf}$ ) was assessed as the amplitude of the first-order decay kinetics of the ECS trace in the first 300 ms [ECSt, (Kanazawa \& Kramer, 2002; Kanazawa et al., 2017)].

Photoprotection (the rapidly reversible form of $\mathrm{NPQ}, q \mathrm{E}$ ) and photo-inhibitory quenching (the slowly relaxing form of NPQ, $q_{\text {I }}$ ) were assessed as described in (Tietz, Hall, Cruz, \& Kramer, 2017), using the MultispeQ V1 or DEPI platform. Briefly, following initial pulses to determine $\mathrm{F}_{\mathrm{O}}$ ' and $\mathrm{F}_{\mathrm{M}}$ ', leaves were dark adapted for 2 min after which $q$ E would have relaxed, leaving $q_{\mathrm{I}}$, enabling us to determine $\mathrm{F}_{\mathrm{M}}$ ".

\section{Gas exchange measurements}

All measurements were assessed with the LI-COR 6800 photosynthesis system with light provided by the light emitting diodes (LEDs) in the fluorescence head. $\mathrm{CO}_{2}$ concentration in the air $\left(C_{\text {a }}\right)$ was set to $400 \mathrm{ppm}$, whereas the light intensity was set to the ambient light intensity in the chamber, which also corresponded to the light intensity treatment. Air temperature in the leaf chamber was also set to the ambient air temperature in the chamber. RH was set to 35 or $50 \%$ for the HT and control treatments respectively. The vapor pressure deficit ranged from 1.5 to $1.9 \mathrm{kPa}$ for the control and 2.5 to $5 \mathrm{kPa}$ for temperatures $35{ }^{\circ} \mathrm{C}$ to $45{ }^{\circ} \mathrm{C}$.

The $A / C$ i measurements were performed using the auto program settings in the LI-COR 6800 instrument with the following sequence of $\mathrm{CO}_{2}$ concentration in the chamber: 400, 200,50,100,150,250,300,350, $500,600,800$ and $1000 \mathrm{ppm} . \mathrm{CO}_{2}$ levels were changed at 2 min intervals to prevent complete deactivation of rubisco at certain low $\mathrm{CO}_{2}$ concentration, especially under $\mathrm{HT}$ conditions. The $2 \mathrm{~min}$ was also sufficient to reach the new $\mathrm{CO}_{2}$ setpoints and establish steady photosynthetic rates. $A / C$ i analyses were performed according to Sharkey et al. (Sharkey, Bernacchi, Farquhar, \& Singsaas, 2007), using an improved version of the Excel Sheet from (Sharkey, 2016). Representative individual curves were fitted separately and the extracted parameters were averaged across replicates for each treatment.

\section{Lincomycin treatment}

Lincomycin treatments have generally involved infiltration of detached leaves with the lincomycin solution (e.g. Davis et al., 2016; Yang et al., 2007). For the HT treatment in cowpea, however, we found that detached leaves resulted in strong declines in PSII efficiency contrary to what we observed in attached leaves. Therefore, our treatments were either through watering of soil with lincomycin solution or syringe infiltration of attached leaves with lincomycin solution. Both approaches gave similar results, although watering the soil had a slower response (in the order of several hours to days) since uptake was generally slow. For the syringe infiltration, effects were seen within a few hours. Briefly, the abaxial side of the leaf was infiltrated with $0.45 \mathrm{mM}$ lincomycin hydrochloride using a syringe by the solution. Control plants were mock infiltrated with deionized water. Following infiltration, plants were kept under low light $\left(50 \mu \mathrm{mol} \mathrm{m} \mathrm{m}^{-2} \mathrm{~s}^{-1}\right)$ for $30 \mathrm{~min}$ to keep the stomata open and then $1 \mathrm{~h}$ in the dark before the HL treatment was imposed (GT+HL). For the HT+HL treatment, the temperature was increased to $40{ }^{\circ} \mathrm{C} 1 \mathrm{~h}$ after initiation of $\mathrm{HL}$ and to $45^{\circ} \mathrm{C}$ after another $1 \mathrm{~h}$. 
The temperature was kept at $45^{\circ} \mathrm{C}$ for the next $5 \mathrm{~h}$.

Determination of photorespiration

The velocity of rubisco for oxygenation ( $v_{\mathrm{o}}$ - used as a proxy for photorespiration) and for carboxylation $\left(v_{\mathrm{c}}\right)$ were calculated from rubisco kinetics using the following equations as described in (Busch, 2013):

$v_{c}=\frac{A+R_{l}}{1-\frac{\Gamma^{*}}{C_{c}}}(1)$

$v_{o}=2 \bullet\left(v_{c}-A-R_{l}\right)(2)$

where $A$ is net assimilation as measured from gas exchange, $C_{\mathrm{c}}$ is $\mathrm{CO}_{2}$ concentration in the chloroplast, and $R_{\mathrm{l}}$ is the day (light) respiration, which is also referred to by $R_{\mathrm{d}}$.

The temperature response function of Bernacchi and others (Bernacchi, Singsaas, Pimentel, Portis Jr, \& Long, 2001; Bernacchi, Portis, Nakano, von Caemmerer, \& Long, 2002) were used $g$ m $\left(\right.$ needed $\left.C_{\mathrm{c}}\right)$, $\Gamma^{*}$ and $R_{1}$ at different temperatures. $\mathrm{v}_{\mathrm{c}}$ calculated using other parameters from the gas exchange measurements or estimated based on data for soybean (Walker et al., 2017). A sample excel sheet for the calculation is attached as supplementary material.

The electron transport rate from gas exchange $\left(\mathrm{ETR}_{\mathrm{GE}}\right)$ was calculated using the following equation:

$\mathrm{ETR}_{\mathrm{GE}}=4 \bullet\left(v_{c}+v_{o}\right)(3)$

To enable direct comparison with the electron transport rate (ETR) obtained by chlorophyll fluorescence, the ETR assessed with LI-COR 6800 simultaneously with gas exchange parameters were used.

Data analysis

Depending on the experiment, we used 2-way (repeated measures) or 3-way ANOVA to determine differences and interactions between treatments (light intensity, temperature and/ or leaf maturity). Means separation was by Tukey's honestly significant difference (HSD) test. Two-sample t-test was also used on specific datasets. Data analysis was performed in Genstat 18th Edition (VSNi, UK), Origin Pro 2019b (OriginLab Corp, Northampton, MA, USA) or in R version 3.6.1 (R Core Team, 2019).

\section{RESULTS AND DISCUSSION}

Effects of short-term exposure to elevated temperature on the partitioning of energy to photoprotection and photochemistry

To determine the effect of light intensity on the temperature response of cowpea, 4-or 11- d-old-seedlings of two genotypes, Yacine (HL-tolerant) and 58-77 (HL-sensitive), were exposed to 300, 1000 or $1500 \mu \mathrm{mol}$ photons $\mathrm{m}^{-2} \mathrm{~s}^{-1} \mathrm{PAR}$ while the temperature was increased by $5{ }^{\circ} \mathrm{C}$ every $2 \mathrm{~h}$ starting from $\mathrm{GT}\left(30{ }^{\circ} \mathrm{C}\right)$ to $\mathrm{HT}\left(45^{\circ} \mathrm{C}\right)$. Following these treatments, the plants were returned to GT for another $1 \mathrm{~h}$ to assess the ability to recover from the treatments.

Figure 1 shows the responses of photosynthetic parameters in Yacine to the temperature regime. Similar results were obtained in the HL-sensitive line, 58-77 (Supplementary Figure 1A). At LL $\left(300 \mu \mathrm{mol} \mathrm{m}^{-2} \mathrm{~s}^{-1}\right)$, $F_{I I}$ in young leaves remained nearly constant as the temperature was increased, consistent with electron flow predominantly light-limited. Mature leaves showed $F_{I I}$ values that decreased significantly $(\mathrm{p}<0.001)$ with increasing temperature, down by $\sim 10 \%$ of initial values at $45{ }^{\circ} \mathrm{C}$, similar to earlier reports in tomato (Meng et al., 2017), At 1000 and $1500 \mu \mathrm{mol} \mathrm{m} \mathrm{m}^{-2} \mathrm{~s}^{-1}$, mature leaves showed only small changes in $F_{I I}$ with temperature, but young leaves showed $F_{I I}$ that increased significantly (by about $30 \% \mathrm{p}<0.001$ ) as temperature was increased to $45{ }^{\circ} \mathrm{C}$, likely indicating an increase in the capacity for photochemistry, possibly reflecting an increase in heat tolerance with illumination as reported earlier (Havaux et al., 1991; Weis, 1985).

The relatively small effect of temperature on $F_{I I}$ is somewhat surprising given the expected strong temperature dependence of photosynthetic reactions and suggests that photosynthesis is subject to compensatory 
regulation or control by multiple processes. All of these effects were reversed, suggesting that they were not caused by irreversible changes.

In all cases, short-term exposure to increasing temperature led to reversible decreases in light-induced thylakoid pmf , as estimated by the amplitude of the dark-interval relaxation kinetics (DIRK) of the electrochromic shift [ECSt, Figure 1B (Takizawa et al., 2007)]. The decreases in pmf can be attributed to increased thylakoid proton conductivity, $\mathrm{g} \mathrm{H}_{\mathrm{H}}^{+}$, estimated from ECS decay kinetics (Baker, Harbinson, \& Kramer, 2007; Kanazawa \& Kramer, 2002; Kramer, Avenson, \& Edwards, 2004) (see Figure 1C), and thus likely reflects increased ATP synthase activity (Kanazawa \& Kramer, 2002) as was seen previously with moderate temperature increases in other species (Zhang \& Sharkey, 2009; Zhang et al., 2009), although other factors such as proton slippage or membrane leakage cannot be ruled out. The pmf , acting through its $\mathrm{pH}$ component, is suggested to be responsible for activating $q \mathrm{E}$ ( $\mathrm{Li}$ et al., 2002). The exception was mature leaves at low light, for whichpmf decreased, but $g_{\mathrm{H}}{ }^{+}$remained relatively constant with temperature. In this case, the decreases in pmf at higher temperature could be attributed to decreased $F_{I I}$, which should translate into lower proton influx by LEF.

Figure 1D shows the responses of NPQ to temperature. Note that these values were estimated using the $\mathrm{NPQ}_{(\mathrm{T})}$ method (Tietz et al., 2017), which allows for more rapid and less invasive measurements, but results in NPQ values that are typically higher than those obtained with the classical method. In the case of older leaves, $\mathrm{NPQ}_{(\mathrm{T})}$ (the sum of $q_{\mathrm{I}(\mathrm{T})}$ and $q_{\mathrm{E}(\mathrm{T})}$ ) increased with temperature, but the opposite behavior was observed in younger leaves (Figure 1D), though in all cases the changes were relatively modest. In general, changes in total $\mathrm{NPQ}_{(\mathrm{T})}$ were inversely related to changes in $F_{I I} \cdot \mathrm{NPQ}_{(\mathrm{T})}$ was reversed during the recovery

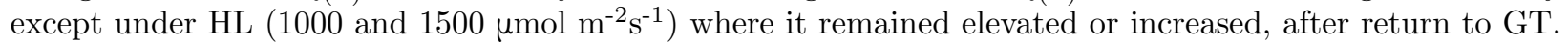
The $q_{\mathrm{L}}$ fluorescence parameter, which estimates the fraction of PSII centers with oxidized $\mathrm{Q}_{\mathrm{A}}$ (Kramer, Johnson, Kiirats, \& Edwards, 2004) increased by $\sim 25 \%$ at the highest temperature in HL, regardless of leaf age (Figure 1E). This result implies that electrons did not accumulate on the intersystem electron transfer chain, suggesting that changes in the capacity for LEF were compensated for by complementary adjustments in $\mathrm{NPQ}_{(\mathrm{T})}$ so that the quantum yield of unregulated energy dissipation $\left(F_{\mathrm{NO}}\right)$ remained relatively constant over the course of the experiment (Supplementary Figure 1B).

CEF has been reported to increase under HT conditions in some species (Essemine, Qu, Mi, \& Zhu, 2016; Sun, Geng, Du, Yang, \& Zhai, 2017), possibly to provide extra ATP needed to maintain metabolic processes, or to maintain pmf and initiate $p m f$-related regulation of light capture and electron flow. Figure $1 \mathrm{~F}$ plots the relative flux of protons through the ATP synthase $\left(v_{\mathrm{H}}{ }^{+}\right)$, estimated by the decay of the DIRK or the ECS signal, against LEF. Increases in the ratio $\left(v_{\mathrm{H}}{ }^{+} / \mathrm{LEF}\right)$ would indicate elevated CEF relative to LEF (Livingston, Kanazawa, Cruz, \& Kramer, 2010; Strand et al., 2015; (Walker, Strand, Kramer, \& Cousins, 2014)). The slope of $v_{\mathrm{H}}{ }^{+} / \mathrm{LEF}$ is also dependent on the content of chloroplasts and ECS-active pigments. Thus, without calibration, we cannot directly compare slopes between leaves of different developmental stages. However, we can assess changes over short time periods, and thus we normalize the ratios to those obtained at $30{ }^{\circ} \mathrm{C}$ and note that in the mature leaves, generally the ratio increased with temperature (Figure $1 \mathrm{G}$ ) at HL (both 1000 and $1500 \mu \mathrm{mol} \mathrm{m} \mathrm{s}^{-2} \mathrm{~s}^{-1}$ ), but declined in LL. Since we know that $F_{I I}$ and thus LEF increased slightly or remained nearly constant in mature leaves with increasing temperature, the only way that the ratio would increase in HL is for CEF to increase. Thus, this data suggests that CEF increased with temperature in mature leaves under HL. On the other hand, the ratio declined with increasing temperature in young leaves, regardless of light intensity, indicating that CEF decreased with temperature. The observation in mature leaves is consistent, whereas that in the young leaves is contrary to earlier reports (Sun et al., 2017), suggesting different responses in leaves of different ages.

Photoinhibition of PSII is controlled by altering the rates of damage and repair processes (Aro et al., 1993; Murata, Takahashi, Nishiyama, \& Allakhverdiev, 2007; Nishiyama \& Murata, 2014), and it is possible that HT impacts one or more of these processes. We thus compared the effects of lincomycin, an inhibitor of chloroplast protein translation that abolishes PSII repair (Tyystjärvi \& Aro, 1996), on changes in maximal PSII quantum efficiency $\left(F_{V} / F_{M}\right)$, measured 20 min after exposure to light, to dissipate $q$ E (Figure 2 ). 
Exposure to $1500 \mu \mathrm{mol} \mathrm{m} \mathrm{m}^{-2} \mathrm{~s}^{-1}$ at GT $(\mathrm{GT}+\mathrm{HL})$ over a period of six hours resulted in a loss of $F_{V} / F_{M}$ of about $50 \%$ in the presence of lincomycin, but only $\sim 20 \%$ in the absence of the inhibitor, suggesting that the HL treatments induced substantial photodamage, which was partly reversed by repair. On the other hand, the loss of $F_{V} / F_{M}$ in the presence of lincomycin was only $\sim 25 \%$ when the temperature was ramped from 30 to $45{ }^{\circ} \mathrm{C}$ during exposure to $\mathrm{HL}$ (HT+HL), implying that $\mathrm{HT}$ decreased the rate of PSII photodamage. The fact that $F_{V} / F_{M}$ deceased only slightly under HT in the absence of lincomycin, suggests that the lower rate of PSII photodamage and repair were able to maintain nearly full PSII efficiency.

Overall, the results in Figure 2 imply that photoinhibition was lower at HT+HL, both because of decreased rates of PSII damage and relatively unhindered rates of PSII repair. This view is consistent with the increased $q$ L and decreased pmf at HT (discussed above), which could ameliorate PSII photodamage caused by recombination reactions that would otherwise lead to ${ }^{1} \mathrm{O}_{2}$ production (Davis et al., 2016). An increase in PSII repair with temperature was proposed to contribute to the tolerance to HT observed in tobacco with enhanced synthesis of the osmoprotectant, glycine betaine (Yang et al., 2007).

Effects of high temperature on $\mathrm{CO}_{2}$ assimilation and photorespiration

Figure 3 shows temperature response curves for net $\mathrm{CO}_{2}$ assimilation $(A)$ under conditions similar to those used in Figure 1. For simplicity, we present data on young leaves in the main text, but found similar results with mature leaves, as presented in Supplementary Figure 2. At LL $\left(300 \mu \mathrm{mol} \mathrm{m}{ }^{-2} \mathrm{~s}^{-1}\right), A$ declined steadily as temperature was increased from 30 to $45{ }^{\circ} \mathrm{C}$ (Figure 3A), but recovered fully (even increasing slightly) after returning to growth temperature. Under 1000 or $1500 \mu \mathrm{mol} \mathrm{m} \mathrm{m}^{-2} \mathrm{~s}^{-1}, A$ remained relatively constant from $30-40{ }^{\circ} \mathrm{C}$, but decreased significantly $(\mathrm{p}<0.01)$ by $20 \%$ from $40-45^{\circ} \mathrm{C}$, consistent with previous work on other species (Crafts-Brandner \& Salvucci, 2002; Lu et al., 2017). Similar to what was found in Loblolly pine (Pinus taeda ) and eastern cottonwood (Populus deltoides ) (Urban, Ingwers, McGuire, \& Teskey, 2017a, 2017b), temperature-dependent decreases in $A$ were not related to $g_{\mathrm{s}}$, which increased with temperature $(\mathrm{p}<0.01)$ under all light intensities but recovered when returned to growth temperature (Figure 3B). Indeed, $C{ }_{\mathrm{i}}$ increased with temperature (Figure 3C and Supplementary Figure 2C), due to increased $g_{s}$ and decreased $A$. These results imply that the drop in $A$ was likely related to decreased carboxylation or increased oxygenation. It is possible that rubisco was deactivated (Salvucci \& Crafts-Brandner, 2004) and/or, as is well established, the specificity for $\mathrm{CO}_{2}$ over $\mathrm{O}_{2}$ declined with increasing temperature (Brooks \& Farquhar, 1985; Galmés et al., 2016; Prins et al., 2016).

velocities of rubisco carboxylation $\left(v_{\mathrm{c}}\right)$ and oxygenation $\left(v_{\mathrm{o}}-\right.$ used as a proxy for photorespiration) (Figures $4 \mathrm{~A}$ and B) from the gas exchange data shown in Figure 3. Results from experiments taken at $1500 \mu \mathrm{mol} \mathrm{m} \mathrm{m}^{-2} \mathrm{~s}^{-1}$ were omitted because they were very similar to those observed at $1000 \mu \mathrm{mol} \mathrm{m} \mathrm{m}^{-2}$. At LL $\left(300 \mu \mathrm{mol} \mathrm{m} \mathrm{m}^{-2} \mathrm{~s}^{-1}\right.$, Figure $\left.4 \mathrm{~A}\right), v_{\mathrm{c}}$ and $v_{\mathrm{o}}$ remained relatively constant over temperature with $v_{\mathrm{o}} / v_{\mathrm{c}}$ ratio of about 0.3 . However, at $\mathrm{HL}\left(1000 \mu \mathrm{mol} \mathrm{m} \mathrm{s}^{-2}\right.$, Figure $\left.4 \mathrm{~B}\right), v_{\circ}$ more temperature-dependent and increased by more than $36 \%$ at $45{ }^{\circ} \mathrm{C}$ compared to $v_{c}$, which only increased by about $16 \%$. These effects were independent of leaf age.

This increase in photorespiration over $\mathrm{CO}_{2}$ assimilation can account for some of the reduction in net $\mathrm{CO}_{2}$ assimilation at HT. It is also possible that some LEF was diverted into "alternative" electron sinks (not related to assimilation or photorespiration) at HT. These sinks include the Mehler-peroxidase reaction (MPR, water-water cycle) (Asada, 2000; Miyake, 2010), the plastid terminal oxidase (PTOX) (Rumeau, Peltier, \& Cournac, 2007), nitrogen (N) reduction, and lipid biosynthesis.

To assess this possibility, we compared the electron transport rate (ETR) measured by chlorophyll fluorescence with that calculated from gas exchange $\left(\mathrm{ETR}_{\mathrm{GE}}\right)$. The difference between the two parameters indicates flow of electrons that cannot be accounted for by carbon fixation and photorespiration. Figure $4 \mathrm{C}$ shows that under LL, in mature leaves, there was no significant $(\mathrm{p}>0.05)$ difference between ETR and $\mathrm{ETR}_{\mathrm{GE}}$ at $30{ }^{\circ} \mathrm{C}$, but the difference increased significantly $(\mathrm{p}=0.03)$ at $45{ }^{\circ} \mathrm{C}$, due to a decrease in $\mathrm{ETR}_{\mathrm{GE}}$ which likely stems

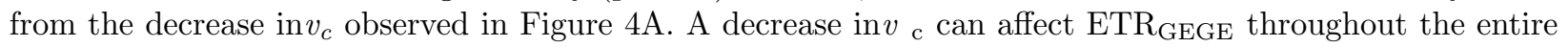
temperature range, except during recovery when $\mathrm{ETR}_{\mathrm{GE}}$ in both leaves increased to the level of ETR. This 
suggests the persistence of alternative electron acceptors, whose activity likely reduced following recovery.

In HL however, upon increasing the temperature to $45^{\circ} \mathrm{C}$, there was no significant difference $(\mathrm{p}=0.9)$ between

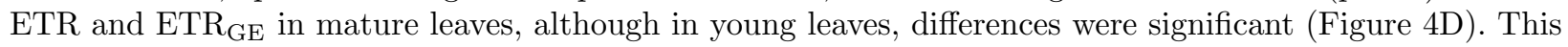
strongly suggests that, at $\mathrm{HT}+\mathrm{HL}$ and especially in mature leaves, the utilization of electrons by $\mathrm{CO}_{2}$ assimilation and photorespiration could account for most of the electrons coming from the light reactions. Nevertheless, in young leaves, there is evidence for the existence of a large pool of alternate electron acceptors which were active regardless of temperature. These results are generally consistent with the $\mathrm{H}^{+} / \mathrm{LEF}$ data in Figure $1 \mathrm{~F}-\mathrm{G}$, which shows elevated CEF in mature leaves but a decline in young leaves under HT+HL. Thus, the case in the mature leaves is generally consistent with an increase in processes with higher ATP demand, such as photorespiration. The low CEF in young leaves is consistent with more active alternative electron acceptors, although photorespiration was also increased as shown in Figure 4B.

The larger alternative electron flow in young leaves could be explained by more electron consuming processes. Such processes include nitrogen metabolism and lipid synthesis, electrons from the light reactions, although these were not directly assayed in this study. Differential nitrogen metabolism between young and mature leaves has been reported in other species and stresses, e.g. in rice (Wang, Wu, Han, Zheng, \& Yang, 2012). There have also been reports that nitrate $\left(\mathrm{NO}_{3}{ }^{-}\right.$) reduction can use up to $25 \%$ of electrons from LEF (Bloom, Caldwell, Finazzo, Warner, \& Weissbart, 1989). Considering that the Hoagland's nutrient solution used to fertilize the cowpea plants in our experiments provide nitrogen mostly as $\mathrm{NO}_{3}{ }^{-}$, this explanation may account for at least some of the alternative electron sinks.

, photons going to alternative electron acceptors also increased. These observations suggest that the combined activity of photorespiration and other alternate electron acceptors could account for a significant portion of electrons from LEF under HT, especially in HL, although, photorespiration was the dominant electron acceptor when considering the relative change in photon or electron utilization.

Figure 5 shows $A / C$ i curves with concurrent chlorophyll fluorescence measurements for young leaves under both GT $\left(30{ }^{\circ} \mathrm{C}\right)$ and $\mathrm{HT}\left(45{ }^{\circ} \mathrm{C}\right)$ at 300 and $1000 \mu \mathrm{mol}$ photons $\mathrm{m}^{-2} \mathrm{~s}^{-1}$ and under ambient $(21 \%)$ and low (1\%) $\mathrm{O}_{2}$ atmospheres. Similar results were obtained for mature leaves (Supplementary Figure 5). A summary of the fitted parameters based on Sharkey et al. (Sharkey et al., 2007; Sharkey, 2016) is shown in Supplementary Figure 4.

As described in detail in the Materials and methods, the measurements were performed sequentially, starting at ambient $\mathrm{CO}_{2}(400 \mathrm{ppm})$ followed by lowering $\mathrm{CO}_{2}$ to $50 \mathrm{ppm}$ through $200 \mathrm{ppm}$ and followed by a gradual rise to high $\mathrm{CO}_{2}$ levels $(1000 \mathrm{ppm})$. Under $300 \mu \mathrm{mol}$ photons $\mathrm{m}^{-2} \mathrm{~s}^{-1}$ and $30{ }^{\circ} \mathrm{C}$ (Figure $5 \mathrm{~A}$ ), $A$ increased with $\mathrm{CO}_{2}$ over the entire range measured. In low oxygen, $A$ appeared to become saturated with $\mathrm{CO}_{2}$. In Figure $5 \mathrm{~B}$, $\mathrm{ETR} / 4$ was mostly independent of $\mathrm{CO}_{2}$ indicating the $\mathrm{RuBP}$ regeneration was the rate determining process. In 1 and $21 \% \mathrm{O}_{2} \mathrm{ETR} / 4$ was about the same except that in $1 \% \mathrm{O}_{2} \mathrm{ETR} / 4$ declined at low $\mathrm{CO}_{2}$, the behavior that indicates RuBP-saturated rubisco kinetics was rate determining. The initial measurement at $400 \mathrm{ppm}$ (circled data) fell on the line observed during the $\mathrm{CO}_{2}$ response curve measurement.

Under $300 \mu \mathrm{mol}$ photons $\mathrm{m}^{-2} \mathrm{~s}^{-1}$ and $45{ }^{\circ} \mathrm{C}$, the data were similar (Figure $5 \mathrm{C}$ and $\mathrm{D}$ ) except that the decline in ETR/4 at low $\mathrm{CO}_{2}$ was more pronounced, indicating the RuBP-saturated rubisco kinetics were more limiting than at $30{ }^{\circ} \mathrm{C}$. Initial measurements (circled) were the same as measurements made during the response curve analysis. Because the maximum ETR/4 was the same at 1 and $21 \% \mathrm{O}_{2}$ at both temperatures there was no indication of triose phosphate use limitation, as would be expected at this moderate light intensity.

The responses were different at $1000 \mu \mathrm{mol}$ photons $\mathrm{m}^{-2} \mathrm{~s}^{-1}$. In $21 \% \mathrm{O}_{2}$ and $30{ }^{\circ} \mathrm{C}$, the initial response of $A$ to $C_{i}$ was much steeper and the $\mathrm{CO}_{2}$ dependence of ETR/4 indicated a significant control by rubisco up to $\sim 200 \mathrm{ppm}$ (compare Figure $5 \mathrm{~B}$ with $5 \mathrm{~F}$ ). In Figure $5 \mathrm{E}, A$ at 1 and $21 \% \mathrm{O}_{2}$ reach the same rate and then are independent of $\mathrm{CO}_{2}$. This has been labeled the triose phosphate use limitation (Sharkey 1985a), which can often be observed at saturating light and slightly higher $C_{i}$ than the leaves likely experienced during growth. Because of photorespiration, when $A$ in 1 and $21 \% \mathrm{O}_{2}$ is the same at the same $C_{i}, \mathrm{ETR} / 4$ must be 
higher at $21 \% \mathrm{O}_{2}$ as was observed (Figure $5 \mathrm{~F}$ ). Because $A$ was the same at 1 and $21 \% \mathrm{O}_{2}$ and no reverse sensitivity was observed there is no evidence for photorespiration increasing $A$ by providing amino acids to the plant as is sometimes observed (Busch et al. 2018). Initial measurements (circled) fell on the same line as determined during the measurements from low to high $\mathrm{CO}_{2}$ (Figure $5 \mathrm{E}$ and $\mathrm{F}$ ). The behaviors reported in Figure $5 \mathrm{~A}$ through $\mathrm{F}$ show the expected relationships among $A$, ETR/4, light, and $C_{i}$ (Sharkey 1985b)

In $1000 \mu \mathrm{mol}$ photons $\mathrm{m}^{-2} \mathrm{~s}^{-1}$ and $45{ }^{\circ} \mathrm{C}$, novel behavior was observed. Especially at high $C_{i}, A$ was approximately the same in 1 and $21 \% \mathrm{O}_{2}$ (Figure 5G). This would require higher ETR/4 in $21 \% \mathrm{O}_{2}$, which was observed (Figure $5 \mathrm{H}$ ). However, the $\mathrm{O}_{2}$ insensitivity of $A$ was not correlated with a $C_{i}$ insensitivity (Figure $5 \mathrm{G}$ ). This phenomenon was seen in both young and mature leaves (supplemental Figure 6G) and in both 1000 and $1500 \mu \mathrm{mol}$ photons $\mathrm{m}^{-2} \mathrm{~s}^{-1}$ (supplemental Figure $7 \mathrm{C}$ and $\mathrm{G}$ ). This behavior is not predicted by current gas exchange theory (Sharkey 2016). Also observed only in saturating light and high temperature is a decline in $A$ and ETR/4 between the first measurement (circled) and the same $C_{i}$ measured during the response curve measurements. We suspect this was a change in metabolic state with time but could also have been induced by the low $C_{i}$ experienced during measurements made to construct the curve.

The strong response of both $A$ and ETR/4 to $C_{i}$ in $1000 \mu \mathrm{mol}$ photons $\mathrm{m}^{-2} \mathrm{~s}^{-1}$ and $45{ }^{\circ} \mathrm{C}$ indicates that rubisco activity was determining the behaviors. Rubisco activation is known to decline at high temperature (Salvucci and Crafts-Bradner 2004). The unusual behavior could reflect a variable rubisco activation state at saturating light and high temperature. Study of this unusual behavior including determining how widespread it is, the activation states of rubisco, metabolomics, and more detailed measurements of electron and proton flows may provide insight into how cowpea tolerates high temperature.

Longer-term effects of elevated temperature and fluctuating light on photosynthesis

We have shown that short term HT combined with HL caused a shift toward photochemistry with the increased electron flux attributed to decreased PSII photodamage, enhanced PSII repair and increased photorespiration as well as activity of other alternative electron acceptors. However, it was not clear whether the effects on PSII function were only for a short period or whether it persisted over a relatively longer time scale and under dynamic conditions as occurs in the field. We, therefore, tested the hypothesis that prolonged exposure to HT+HL especially under dynamic conditions could lead to more severe loss in efficiency of PSII for photochemistry $\left(F_{\text {II }}\right)$ under the combined stress relative to HL stress alone. Dynamic (fluctuating) light conditions have been shown to produce phenotypes not detected under constant light conditions normally used in growth chambers (Cruz et al., 2016; J. Li et al., 2019). Figure 6 shows results from a four-day experiment, with altered temperature and light intensity patterns, as indicated above Figure $6 \mathrm{~A}$, to expose the plants to a range of light and temperature conditions. On Day 1, the light intensity was fluctuated between 300 and $1500 \mu \mathrm{mol}$ photons $\mathrm{m}^{-2} \mathrm{~s}^{-1}$ in two steps. On Days 2 and 3, the light was held constant at 1500 and $300 \mu \mathrm{mol}$ photons $\mathrm{m}^{-2} \mathrm{~s}^{-1}$ respectively, and on the final day the fluctuating pattern used on Day 1 was repeated. Plants were also exposed to either a constant GT $\left(30{ }^{\circ} \mathrm{C}\right)$, a constant $\mathrm{HT}\left(45^{\circ} \mathrm{C}\right)$, or a daily fluctuation in temperature between GT in the morning, HT at midday and returning to GT by end of the day (HTR - HT with recovery). The night temperature was kept constant $\left(20^{\circ} \mathrm{C}\right)$ for all treatments, except the constant $\mathrm{HT}$, where it was kept at $35^{\circ} \mathrm{C}$.

Both lines showed decreased $F$ II when exposed to fluctuating and HL under constant GT, but was particularly evident in the HL-sensitive line (58-77) on days 2 through 4 (Figure 6A). The decreased $F$ II was accompanied by increases in long-lived NPQ $\left(q_{\mathrm{I}(\mathrm{T})}\right)$, suggesting that the regiment of light treatments induced substantial photoinhibition or photodamage. By contrast, both regimes with elevated temperatures resulted in smaller losses of PSII activity on Day 4 (Figure 6A), when compared to the initial values at the beginning of Day 1, suggesting that the HT prevented the buildup of photoinhibition. Supplementary Figure 7 shows the $\log _{2}$ fold change of $F$ II which indicates that both HT treatments resulted in relatively higher PSII activity compared GT, especially in HL.

When the temperature was first increased in Day 1, there was an abrupt spike in $\mathrm{NPQ}_{(\mathrm{T})}$ (Figure $6 \mathrm{~B}$ ); the rapid recovery of this spike suggests that it is caused by $q \mathrm{E}(\mathrm{T})$ (Figure $6 \mathrm{D}$ ). This effect was observed in both 
lines, but was larger for Yacine, especially under HL, and was regardless of whether the light was constant or fluctuating. However, with time, NPQ declined, likely due to the decreasing $q \mathrm{E}(\mathrm{T})$, and reached values similar to the GT treatment at the end of the day. By the 4th day, $\mathrm{NPQ}_{(\mathrm{T})}$ and photoprotection $(q \mathrm{E}(\mathrm{T}))$ had declined in Yacine below values of the GT plants. Since $F$ II increased with the decline in NPQ as was seen in Figure 1, it suggests that PSII photodamage was not increased and/or that PSII repair was able to maintain high activity, in line with Figure 2.

By contrast, $q_{\mathrm{I}(\mathrm{T})}$ was persistently low in the HT treatments compared to the GT plants under HL regardless of the light intensity (Figure 6C). Thus, it is possible that the increased $q_{\mathrm{I}(\mathrm{T})}$ in GT resulted in impaired PSII activity as indicated by the low $F_{\text {II }}$ in HL. These results suggest that HT prevented loss of PSII activity under HL by reducing the slowly relaxing form of NPQ. It should be noted that compared to values at the beginning of Day 1, the HT treatment slightly increased $q_{\mathrm{I}(\mathrm{T})}$. However, when compared to GT at the same time points, $q_{\mathrm{I}(\mathrm{T})}$ was lower in both HT treatments. This reduced $q_{\mathrm{I}(\mathrm{IT})}$ is consistent with enhanced activity of alternative electron acceptors, and particularly photorespiration.

The data presented imply that, at least in these cowpea lines and in particular younger leaves, the light reactions of photosynthesis were relatively unimpaired under combined HT + HL as has been reported in tomatoes (Gerganova et al., 2016). Further, these effects apparently persist over a relatively long term and under dynamic light and temperature conditions. Using two genotypes with differing sensitivity to HL revealed that the effects of combined HT and HL were common regardless. In fact, the HL-sensitive genotype, 58-77, appeared to show more tolerance to HL when combined with HT. These observations allude to the fact that cowpea plants are better equipped to deal with the combination of HL and HT stresses since these often occur together in the field. However, it is not known whether the exhibited tolerance of the light reactions would lead to increased productivity since carbon metabolism was inhibited under these conditions.

\section{Conclusions}

Several remarkable results lead us to propose that multiple electron acceptors can protect PSII against photodamage under combined high light and elevated temperatures. One remarkable observation from our work was the nearly temperature-independent responses of the light reactions. Most strikingly, the redox state of $\mathrm{Q}_{\mathrm{A}}$, often taken as a measure of the regulatory balance of the light reactions, tended to become more oxidized as temperature increased (Figure 1E). These results imply that, even as assimilation was significantly reduced by temperature, the light reactions were stimulated (rather than inhibited) in a light intensity dependent manner. Under fluctuating light conditions, increasing temperature increased $F$ II,

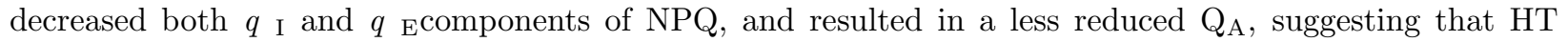
decreased the accumulation of states that would normally result in photodamage (Figure 6). These effects were more pronounced following acclimation to HT and fluctuating/high light. Separate experiments suggest that the rates of photodamage are decreased and the rates of PSII repair increased under HT.

The small impact of temperature on the light reactions can in large part be explained by the fact that the sinks for electrons from LEF remained highly active. When $A$ decreased, electrons flowed to other electron acceptors. A large fraction of these acceptors can be accounted for by increased photorespiration, but an additional fraction appears to be sent to a light intensity dependent process, possibly involving $\mathrm{O}_{2}$ reduction by a process with a relatively low $K{ }_{\mathrm{m}}$ for $\mathrm{O}_{2}$, or other metabolic electron sinks.

Similarly, the regulation (or control) of the light reactions through the pmf was less engaged at higher temperatures, with increased ATP synthase activity $\left(g_{\mathrm{H}}^{+}\right)$, and decreased $p m f$ (Figure 1). This combination of increased LEF and high $g_{\mathrm{H}}{ }^{+}$are consistent with increases in sinks for both electrons and ATP, i.e. there did appear to be a depletion of sinks or substrates for ATP synthase. These results pose an interesting question: how is the supply of outputs of ATP and NADPH from the light reactions maintained in balance with metabolic demand despite the diversion of energy to alternative processes? In particular, photorespiration requires additional ATP/NADPH compared to the $\mathrm{CBB}$ cycle, and one might expect that ATP supplementation would be required under high photorespiratory conditions at HT. However, CEF (Figure 1F-G), which is thought to supplement ATP under such conditions (Strand, Fisher, \& Kramer, 2017), actually decreased 
under elevated temperatures in the young leaves, suggesting that other processes allowed for ATP/NADPH balance. One possibility is alternative electron flow to $\mathrm{O}_{2}$, as suggested by comparisons of ETR calculated from the sum of the velocity for carboxylation and oxygenation $\left(\mathrm{ETR}_{\mathrm{GE}}\right.$, Figure 4$)$ and chlorophyll fluorescence (ETR), which should have increased ATP production without net changes in NADPH (Miyake, 2010). On the other hand, in mature leaves, CEF increased in HL, consistent with the increased photorespiration accounting for a large fraction of electrons under HT (Figure 4). In either case, we show clear evidence that photorespiration is an essential electron sink that appears to help maintain open PSII redox sites under high light and temperature stresses.

A second remarkable observation is the light intensity-and temperature-dependent down-regulation or inhibition of rubisco activity at low $\mathrm{O}_{2}$ in (Figure 5, Supplementary Figure 5 and 6). This effect can most easily be explained by deactivation of rubisco itself, though our data cannot rule out other indirect effects that result in apparent loss of rubisco activity estimated by gas exchange. Nevertheless, the effect was mostly seen in $\mathrm{HL}$, but was more pronounced at $\mathrm{HT}$ and under low $\mathrm{CO}_{2}$ conditions, and was rapidly reversible upon increasing $\mathrm{CO}_{2}$, suggesting that it serves a regulatory role.

Overall, cowpea appears to have mechanisms that allow the light reactions to maintain high activity and low propensity for ROS generation, through a combination of highly active alternative energy sinks, including photorespiration and other, yet undefined, electron sinks. We speculate that breeding or engineering crops to increase the capacity of these sinks could lead to more robust crop productivity under field conditions where acute combined high light and temperature stresses occur.

\section{Acknowledgements}

The authors would like to thank Drs Philip Roberts and Bao Lam Huynh for providing cowpea seeds and along with Drs. Jeffrey Ehlers, Wayne Loescher and Irvin Widders for useful discussions and David Hall for helping with the DEPI experiments.

\section{BIBLIOGRAPHY}

Aro, E. M., Virgin, I., \& Andersson, B. (1993). Photoinhibition of Photosystem II. Inactivation, protein damage and turnover.Biochimica et Biophysica Acta , 1143 (2), 113-134. doi:10.1016/0005-2728(93)90134-2

Asada, K. (2000). The water-water cycle as alternative photon and electron sinks. Philosophical Transactions of the Royal Society of London. Series B, Biological Sciences , 355 (1402), 1419-1431. doi:10.1098/rstb.2000.0703

Avenson, T J, Kanazawa, A., Cruz, J. A., Takizawa, K., Ettinger, W. E., \& Kramer, D. M. (2005). Integrating the proton circuit into photosynthesis: progress and challenges. Plant, Cell ES Environment, 28 (1), 97-109. doi:10.1111/j.1365-3040.2005.01294.x

Avenson, Thomas J, Cruz, J. A., Kanazawa, A., \& Kramer, D. M. (2005). Regulating the proton budget of higher plant photosynthesis.Proceedings of the National Academy of Sciences of the United States of America , 102 (27), 9709-9713. doi:10.1073/pnas.0503952102

Avenson, Thomas J, Cruz, J. A., \& Kramer, D. M. (2004). Modulation of energy-dependent quenching of excitons in antennae of higher plants.Proceedings of the National Academy of Sciences of the United States of America , 101 (15), 5530-5535. doi:10.1073/pnas.0401269101

Baker, N. R., Harbinson, J., \& Kramer, D. M. (2007). Determining the limitations and regulation of photosynthetic energy transduction in leaves. Plant, Cell \& Environment, 30 (9), 1107-1125. doi:10.1111/j.13653040.2007.01680.x

Bauwe, H., Hagemann, M., \& Fernie, A. R. (2010). Photorespiration: players, partners and origin. Trends in Plant Science ,15 (6), 330-336. doi:10.1016/j.tplants.2010.03.006

Bernacchi, C J, Singsaas, E. L., Pimentel, C., Portis Jr, A. R., \& Long, S. P. (2001). Improved temperature 
response functions for models of Rubisco-limited photosynthesis. Plant, Cell $\&$ Environment ,24 (2), 253259. doi:10.1111/j.1365-3040.2001.00668.x

Bernacchi, Carl J, Portis, A. R., Nakano, H., von Caemmerer, S., \& Long, S. P. (2002). Temperature response of mesophyll conductance. Implications for the determination of Rubisco enzyme kinetics and for limitations to photosynthesis in vivo. Plant Physiology ,130 (4), 1992-1998. doi:10.1104/pp.008250

Bloom, A. J., Caldwell, R. M., Finazzo, J., Warner, R. L., \& Weissbart, J. (1989). Oxygen and Carbon Dioxide Fluxes from Barley Shoots Depend on Nitrate Assimilation. Plant Physiology , 91 , 352-356.

Brooks, A., \& Farquhar, G. D. (1985). Effect of temperature on the CO2/O2 specificity of ribulose- 1,5bisphosphate carboxylase/0xygenase and the rate of respiration in the light. Planta , 165 , 397-406.

Buchner, O., Stoll, M., Karadar, M., Kranner, I., \& Neuner, G. (2015). Application of heat stress in situ demonstrates a protective role of irradiation on photosynthetic performance in alpine plants. Plant, Cell $\&$ Environment , 38 (4), 812-826. doi:10.1111/pce.12455

Busch, F. A. (2013). Current methods for estimating the rate of photorespiration in leaves. Plant Biology , 15 (4), 648-655. doi:10.1111/j.1438-8677.2012.00694.x

Busch, F. A., Sage, R. F., Farquhar, G. D. (2018). Plants increase $\mathrm{CO}_{2}$ uptake by assimilating nitrogen via the photorespiratory pathway. Nature Plants 4: 46-54

Butler, W. L. (1978). Energy distribution in the photochemical apparatus of photosynthesis. Annual Review of Plant Physiology ,29 (1), 345-378. doi:10.1146/annurev.pp.29.060178.002021

Chen, Y.-E., Zhang, C.-M., Su, Y.-Q., Ma, J., Zhang, Z.-W., Yuan, M., .. Yuan, S. (2017). Responses of photosystem II and antioxidative systems to high light and high temperature co-stress in wheat.Environmental and experimental botany , 135 , 45-55. doi:10.1016/j.envexpbot.2016.12.001

Crafts-Brandner, S J, \& Salvucci, M. E. (2000). Rubisco activase constrains the photosynthetic potential of leaves at high temperature and CO2. Proceedings of the National Academy of Sciences of the United States of America , 97 (24), 13430-13435. doi:10.1073/pnas.230451497

Crafts-Brandner, Steven J, \& Salvucci, M. E. (2002). Sensitivity of photosynthesis in a C4 plant, maize, to heat stress. Plant Physiology, 129 (4), 1773-1780. doi:10.1104/pp.002170

Cruz, J. A., Savage, L. J., Zegarac, R., Hall, C. C., Satoh-Cruz, M., Davis, G. A., .. Kramer, D. M. (2016). Dynamic environmental photosynthetic imaging reveals emergent phenotypes. Cell Systems ,2 (6), 365-377. doi:10.1016/j.cels.2016.06.001

Cui, L., Li, J., Fan, Y., Xu, S., \& Zhang, Z. (2006). High temperature effects on photosynthesis, PSII functionality and antioxidant activity of two Festuca arundinacea cultivars with different heat susceptibility.Botanical Studies , 47 (1), 61-69.

Davis, G. A., Kanazawa, A., Schöttler, M. A., Kohzuma, K., Froehlich, J. E., Rutherford, A. W., .. Kramer, D. M. (2016). Limitations to photosynthesis by proton motive force-induced photosystem II photodamage. eLife , 5 . doi:10.7554/eLife.16921

Ehlers, J. D., \& Hall, A. E. (1996). Genotypic classification of cowpea based on responses to heat and photoperiod. Crop science ,36 (3), 673. doi:10.2135/cropsci1996.0011183X003600030026x

Ehlers, J. D., \& Hall, A. E. (1998). Heat tolerance of contrasting cowpea lines in short and long days. Field crops research ,55 (1-2), 11-21. doi:10.1016/S0378-4290(97)00055-5

Essemine, J., Qu, M., Mi, H., \& Zhu, X.-G. (2016). Response of Chloroplast NAD(P)H DehydrogenaseMediated Cyclic Electron Flow to a Shortage or Lack in Ferredoxin-Quinone OxidoreductaseDependent Pathway in Rice Following Short-Term Heat Stress. Frontiers in plant science , 7 , 383. doi:10.3389/fpls.2016.00383 
Galmés, J., Hermida-Carrera, C., Laanisto, L., \& Niinemets, Ü. (2016). A compendium of temperature responses of Rubisco kinetic traits: variability among and within photosynthetic groups and impacts on photosynthesis modeling. Journal of Experimental Botany ,67 (17), 5067-5091. doi:10.1093/jxb/erw267

Gamon, J. A., \& Pearcy, R. W. (1989). Leaf movement, stress avoidance and photosynthesis in Vitis californica. Oecologia , 79 (4), 475-481. doi:10.1007/BF00378664

Gerganova, M., Popova, A. V., Stanoeva, D., \& Velitchkova, M. (2016). Tomato plants acclimate better to elevated temperature and high light than to treatment with each factor separately. Plant Physiology and Biochemistry , 104 , 234-241. doi:10.1016/j.plaphy.2016.03.030

Harley, P. C., \& Sharkey, T. D. (1991). An improved model of C 3 photosynthesis at high CO2: Reversed sensitivity explained by lack of glycerate reentry into the chloroplast 02. Photosynthesis Research , 27 , $169-178$.

Hasanuzzaman, M., Nahar, K., Alam, M. M., Roychowdhury, R., \& Fujita, M. (2013). Physiological, biochemical, and molecular mechanisms of heat stress tolerance in plants. International Journal of Molecular Sciences , 14 (5), 9643-9684. doi:10.3390/ijms14059643

Havaux, M. (1992). Stress tolerance of photosystem II in vivo: antagonistic effects of water, heat, and photoinhibition stresses.Plant Physiology , 100 (1), 424-432. doi:10.1104/pp.100.1.424

Havaux, M., Greppin, H., \& Strasser, R. J. (1991). Functioning of photosystems I and II in pea leaves exposed to heat stress in the presence or absence of light: Analysis using in-vivo fluorescence, absorbance, oxygen and photoacoustic measurements. Planta ,186 (1), 88-98. doi:10.1007/BF00201502

Hemming, S. (2011). Use of Natural and Artificial Light in Horticulture - Interaction of Plant and Technology. Acta horticulturae ,907, 26-35.

Huang, W., Hu, H., \& Zhang, S.-B. (2015). Photorespiration plays an important role in the regulation of photosynthetic electron flow under fluctuating light in tobacco plants grown under full sunlight.Frontiers in plant science , 6 , 621. doi:10.3389/fpls.2015.00621

Joly, D., \& Carpentier, R. (2007). Regulation of energy dissipation in photosystem I by the redox state of the plastoquinone pool.Biochemistry , 46 (18), 5534-5541. doi:10.1021/bi602627d

Kalituho, L. N., Pshybytko, N. L., Kabashnikova, L. F., \& Jahns, P. (2003). Photosynthetic apparatus and high temperature: role of light.Bulgarian Journal of Plant Physiology , 281-289.

Kanazawa, A., \& Kramer, D. M. (2002). In vivo modulation of nonphotochemical exciton quenching (NPQ) by regulation of the chloroplast ATP synthase. Proceedings of the National Academy of Sciences of the United States of America , 99 (20), 12789-12794. doi:10.1073/pnas.182427499

Kanazawa, A., Ostendorf, E., Kohzuma, K., Hoh, D., Strand, D. D., Sato-Cruz, M., .. Kramer, D. M. (2017). Chloroplast ATP synthase modulation of the thylakoid proton motive force: implications for photosystem I and photosystem II photoprotection. Frontiers in plant science , 8 , 719. doi:10.3389/fpls.2017.00719

Kramer, D. M., Avenson, T. J., \& Edwards, G. E. (2004). Dynamic flexibility in the light reactions of photosynthesis governed by both electron and proton transfer reactions. Trends in Plant Science ,9 (7), 349-357. doi:10.1016/j.tplants.2004.05.001

Kramer, D. M., \& Evans, J. R. (2011). The importance of energy balance in improving photosynthetic productivity. Plant Physiology ,155 (1), 70-78. doi:10.1104/pp.110.166652

Kramer, D. M., Johnson, G., Kiirats, O., \& Edwards, G. E. (2004). New fluorescence parameters for the determination of QA redox state and excitation energy fluxes. Photosynthesis Research , 79 (2), 209. doi:10.1023/B:PRES.0000015391.99477.0d 
Krause, G. H., Somersalo, S., Zumbusch, E., Weyers, B., \& Laasch, H. (1990). On the Mechanism of Photoinhibition in Chloroplasts. Relationship Between Changes in Fluorescence and Activity of Photosystem II. Journal of Plant Physiology , 136 , 472-479.

Kuhlgert, S., Austic, G., Zegarac, R., Osei-Bonsu, I., Hoh, D., Chilvers, M. I., .. Kramer, D. M. (2016). MultispeQ Beta: a tool for large-scale plant phenotyping connected to the open PhotosynQ network. Royal Society open science, 3 (10), 160592. doi:10.1098/rsos.160592

Li, J., Tietz, S., Cruz, J. A., Strand, D. D., Xu, Y., Chen, J., ... Hu, J. (2019). Photometric screens identified Arabidopsis peroxisome proteins that impact photosynthesis under dynamic light conditions. The Plant Journal: for Cell and Molecular Biology ,97 (3), 460-474. doi:10.1111/tpj.14134

Li, X.-P., Gilmore, A. M., Caffarri, S., Bassi, R., Golan, T., Kramer, D., \& Niyogi, K. K. (2004). Regulation of photosynthetic light harvesting involves intrathylakoid lumen $\mathrm{pH}$ sensing by the PsbS protein. The Journal of Biological Chemistry , 279 (22), 22866-22874. doi:10.1074/jbc.M402461200

Li, X.-P., Muller-Moule, P., Gilmore, A. M., \& Niyogi, K. K. (2002). PsbS-dependent enhancement of feedback de-excitation protects photosystem II from photoinhibition. Proceedings of the National Academy of Sciences of the United States of America , 99 (23), 15222-15227. doi:10.1073/pnas.232447699

Lin, C. H., McGraw, R. L., George, M. F., \& Garret, H. E. (1999). Shade effects on forage crops with potential in temperate agroforestry practices. Agroforestry Systems , 44, 109-119.

Lin, Z., Peng, C., Sun, Z., \& Lin, G. (2000). Effect of light intensity on partitioning of photosynthetic electron transport to photorespiration in four subtropical forest plants. Science in China. Series C, Life Sciences , 43 (4), 347-354. doi:10.1007/BF02879298

Livingston, A. K., Kanazawa, A., Cruz, J. A., \& Kramer, D. M. (2010). Regulation of cyclic electron flow in C3 plants: differential effects of limiting photosynthesis at ribulose-1,5-bisphosphate carboxylase/oxygenase and glyceraldehyde-3-phosphate dehydrogenase.Plant, Cell \& Environment , 33 (11), 17791788. doi:10.1111/j.1365-3040.2010.02183.x

Long, S. P., Humphries, S., \& Falkowski, P. G. (1994). Photoinhibition of photosynthesis in nature. Annual review of plant physiology and plant molecular biology , 45 (1), 633-662. doi:10.1146/annurev.pp.45.060194.003221

Lu, T., Meng, Z., Zhang, G., Qi, M., Sun, Z., Liu, Y., \& Li, T. (2017). Sub-high Temperature and High Light Intensity Induced Irreversible Inhibition on Photosynthesis System of Tomato Plant (Solanum lycopersicum L.). Frontiers in plant science, 8 , 365. doi:10.3389/fpls.2017.00365

Meng, Z., Lu, T., Zhang, G., Qi, M., Tang, W., Li, L., .. Li, T. (2017). Photosystem inhibition and protection in tomato leaves under low light. Scientia horticulturae , 217, 145-155. doi:10.1016/j.scienta.2017.01.039

Miyake, C. (2010). Alternative electron flows (water-water cycle and cyclic electron flow around PSI) in photosynthesis: molecular mechanisms and physiological functions. Plant \& Cell Physiology ,51 (12), 19511963. doi:10.1093/pcp/pcq173

Murata, N., Takahashi, S., Nishiyama, Y., \& Allakhverdiev, S. I. (2007). Photoinhibition of photosystem II under environmental stress.Biochimica et Biophysica Acta , 1767 (6), 414-421. doi:10.1016/j.bbabio.2006.11.019

Nishiyama, Y., \& Murata, N. (2014). Revised scheme for the mechanism of photoinhibition and its application to enhance the abiotic stress tolerance of the photosynthetic machinery. Applied Microbiology and Biotechnology , 98 (21), 8777-8796. doi:10.1007/s00253-014-6020-0

Panigrahi, S., Pradhan, M. K., Panda, D. K., Panda, S. K., \& Joshi, P. N. (2016). Diminution of photosynthesis in rice (Oryza sativa L.) seedlings under elevated $\mathrm{CO} 2$ concentration and increased tempera- 
ture.Photosynthetica , 54 (3), 359-366. doi:10.1007/s11099-016-0190-1

Pastenes, C., Pimentel, P., \& Lillo, J. (2005). Leaf movements and photoinhibition in relation to water stress in field-grown beans. Journal of Experimental Botany , 56 (411), 425-433. doi:10.1093/jxb/eri061

Paul, M. J., \& Foyer, C. H. (2001). Sink regulation of photosynthesis_Paul 2001.pdf. Journal of Experimental Botany ,52 (360), 1383-1400.

Prins, A., Orr, D. J., Andralojc, P. J., Reynolds, M. P., Carmo-Silva, E., \& Parry, M. A. J. (2016). Rubisco catalytic properties of wild and domesticated relatives provide scope for improving wheat photosynthesis. Journal of Experimental Botany , 67 (6), 1827-1838. doi:10.1093/jxb/erv574

R Core Team. (2019). R: A language and environment for statistical computing (3.6.1). Computer software, Vienna, Austria: R Foundation for Statistical Computing.

Ruban, A. V. (2016). Nonphotochemical Chlorophyll Fluorescence Quenching: Mechanism and Effectiveness in Protecting Plants from Photodamage. Plant Physiology , 170 (4), 1903-1916. doi:10.1104/pp.15.01935

Ruban, A. V., Johnson, M. P., \& Duffy, C. D. P. (2012). The photoprotective molecular switch in the photosystem II antenna. Biochimica et Biophysica Acta , 1817 (1), 167-181. doi:10.1016/j.bbabio.2011.04.007

Rumeau, D., Peltier, G., \& Cournac, L. (2007). Chlororespiration and cyclic electron flow around PSI during photosynthesis and plant stress response. Plant, Cell ES Environment , 30 (9), 1041-1051. doi:10.1111/j.1365-3040.2007.01675.x

Salvucci, M. E., \& Crafts-Brandner, S. J. (2004). Inhibition of photosynthesis by heat stress: the activation state of Rubisco as a limiting factor in photosynthesis. Physiologia Plantarum ,120 (2), 179-186. doi:10.1111/j.0031-9317.2004.0173.x

Schuster, W. S., \& Monson, R. K. (1990). An examination of the advantages of C3-C4 intermediate photosynthesis in warm environments.Plant, Cell \& Environment , 13 (9), 903-912. doi:10.1111/j.13653040.1990.tb01980.x

Sharkey, T. D. (1985a). O2-insensitive photosynthesis in C3 plants: Its occurrence and a possible explanation. Plant Physiology 78: 71-75

Sharkey, T. D. (1985b). Photosynthesis in intact leaves of C3 plants: Physics, physiology and rate limitations. The Botanical Review 51: 53-105

Sharkey, T. D. (2005). Effects of moderate heat stress on photosynthesis: importance of thylakoid reactions, rubisco deactivation, reactive oxygen species, and thermotolerance provided by isoprene.Plant, Cell $\mathscr{E}$ Environment , 28 (3), 269-277. doi:10.1111/j.1365-3040.2005.01324.x

Sharkey, T. D. (2016). What gas exchange data can tell us about photosynthesis. Plant, Cell \& Environment , 39 (6), 1161-1163. doi:10.1111/pce.12641

Sharkey, T. D., Seemann, J. R., \& Berry, J. A. (1986). Regulation of Ribulose-1,5-Bisphosphate Carboxylase Activity in Response to Changing Partial Pressure of 02 and Light in Phaseolus vulgaris. Plant Physiology , 81, 788-791.

Sharkey, T. D., \& Vanderveer, P. J. (1989). Stromal Phosphate Concentration Is Low during Feedback Limited Photosynthesis. Plant Physiology , 91 (2), 679-684. doi:10.1104/pp.91.2.679

Sharkey, T. D, Bernacchi, C. J., Farquhar, G. D., \& Singsaas, E. L. (2007). Fitting photosynthetic carbon dioxide response curves for C(3) leaves. Plant, Cell \& Environment, 30 (9), 1035-1040. doi:10.1111/j.13653040.2007.01710.x

Slattery, R. A., Walker, B. J., Weber, A. P. M., \& Ort, D. R. (2018). The impacts of fluctuating light on crop performance. Plant Physiology , 176 (2), 990-1003. doi:10.1104/pp.17.01234 
Stefanov, D., \& Terashima, I. (2008). Non-photochemical loss in PSII in high- and low-light-grown leaves of Vicia faba quantified by several fluorescence parameters including L(NP), F0/F'm, a novel parameter.Physiologia Plantarum , 133 (2), 327-338. doi:10.1111/j.1399-3054.2008.01077.x

Strand, D. D., Fisher, N., \& Kramer, D. M. (2017). The higher plant plastid NAD(P)H dehydrogenase-like complex (NDH) is a high efficiency proton pump that increases ATP production by cyclic electron flow. The Journal of Biological Chemistry, 292 (28), 11850-11860. doi:10.1074/jbc.M116.770792

Strand, D. D., Livingston, A. K., Satoh-Cruz, M., Froehlich, J. E., Maurino, V. G., \& Kramer, D. M. (2015). Activation of cyclic electron flow by hydrogen peroxide in vivo. Proceedings of the National Academy of Sciences of the United States of America , 112 (17), 5539-5544. doi:10.1073/pnas.1418223112

Suetsugu, N., Higa, T., Gotoh, E., \& Wada, M. (2016). Light-Induced Movements of Chloroplasts and Nuclei Are Regulated in Both Cp-Actin-Filament-Dependent and -Independent Manners in Arabidopsis thaliana. Plos One , 11 (6), e0157429. doi:10.1371/journal.pone.0157429

Sun, Y., Geng, Q., Du, Y., Yang, X., \& Zhai, H. (2017). Induction of cyclic electron flow around photosystem I during heat stress in grape leaves. Plant Science , 256 , 65-71. doi:10.1016/j.plantsci.2016.12.004

Takizawa, K., Cruz, J. A., Kanazawa, A., \& Kramer, D. M. (2007). The thylakoid proton motive force in vivo. Quantitative, non-invasive probes, energetics, and regulatory consequences of light-induced pmf.Biochimica et Biophysica Acta , 1767 (10), 1233-1244. doi:10.1016/j.bbabio.2007.07.006

Tan, W., Meng, Q. wei, Brestic, M., Olsovska, K., \& Yang, X. (2011). Photosynthesis is improved by exogenous calcium in heat-stressed tobacco plants. Journal of Plant Physiology , 168 (17), 2063-2071. doi:10.1016/j.jplph.2011.06.009

Tietz, S., Hall, C. C., Cruz, J. A., \& Kramer, D. M. (2017). NPQ(T) : a chlorophyll fluorescence parameter for rapid estimation and imaging of non-photochemical quenching of excitons in photosystem-II-associated antenna complexes. Plant, Cell \& Environment , 40 (8), 1243-1255. doi:10.1111/pce.12924

Tikhonov, A. N. (2014). The cytochrome b6f complex at the crossroad of photosynthetic electron transport pathways. Plant Physiology and Biochemistry , 81 , 163-183. doi:10.1016/j.plaphy.2013.12.011

Tyystjärvi, E., \& Aro, E. M. (1996). The rate constant of photoinhibition, measured in lincomycin-treated leaves, is directly proportional to light intensity. Proceedings of the National Academy of Sciences of the United States of America , 93 (5), 2213-2218. doi:10.1073/pnas.93.5.2213

Urban, J., Ingwers, M., McGuire, M. A., \& Teskey, R. O. (2017a). Stomatal conductance increases with rising temperature. Plant Signaling \& Behavior , 12 (8), e1356534. doi:10.1080/15592324.2017.1356534

Urban, J., Ingwers, M. W., McGuire, M. A., \& Teskey, R. O. (2017b). Increase in leaf temperature opens stomata and decouples net photosynthesis from stomatal conductance in Pinus taeda and Populus deltoides x nigra. Journal of Experimental Botany , 68 (7), 1757-1767. doi:10.1093/jxb/erx052

Voss, I., Sunil, B., Scheibe, R., \& Raghavendra, A. S. (2013). Emerging concept for the role of photorespiration as an important part of abiotic stress response. Plant Biology , 15 (4), 713-722. doi:10.1111/j.14388677.2012.00710.x

Wada, M. (2013). Chloroplast movement. Plant Science , 210 , 177-182. doi:10.1016/j.plantsci.2013.05.016

Walker, B. J., Kramer, D. M., Fisher, N., \& Fu, X. (2020). Flexibility in the Energy Balancing Network of Photosynthesis Enables Safe Operation under Changing Environmental Conditions. Plants, 9(3). doi:10.3390/plants9030301

Walker, B. J.; Orr, D. J.; Carmo-Silva, E.; Parry, M. A. J.; Bernacchi, C. J.; Ort, D. R., (2017). Uncertainty in measurements of the photorespiratory $\mathrm{CO} 2$ compensation point and its impact on models of leaf photosynthesis. Photosynthesis Research, 1-11. 
Walker, B. J., Strand, D. D., Kramer, D. M., \& Cousins, A. B. (2014). The response of cyclic electron flow around photosystem I to changes in photorespiration and nitrate assimilation. Plant Physiology, 165(1), 453-462. doi:10.1104/pp.114.238238

Wang, H., Wu, Z., Han, J., Zheng, W., \& Yang, C. (2012). Comparison of ion balance and nitrogen metabolism in old and young leaves of alkali-stressed rice plants. Plos One , 7 (5), e37817. doi:10.1371/journal.pone.0037817

Weis, E. (1982). Influence of Light on the Heat Sensitivity of the Photosynthetic Apparatus in Isolated Spinach Chloroplasts. Plant Physiology, 70 , 1530-1534.

Weis, E. (1985). Light- and temperature-induced changes in the distribution of excitation energy between Photosystem I and Photosystem II in spinach leaves. Biochimica et Biophysica Acta (BBA) - Bioenergetics , 807 (2), 118-126. doi:10.1016/0005-2728(85)90114-8

Wise, R. R., Olson, A. J., Schrader, S. M., \& Sharkey, T. D. (2004). Electron transport is the functional limitation of photosynthesis in field-grown Pima cotton plants at high temperature. Plant, Cell and Environment , 27 (6), 717-724.

Yang, X., Wen, X., Gong, H., Lu, Q., Yang, Z., Tang, Y., .. Lu, C. (2007). Genetic engineering of the biosynthesis of glycinebetaine enhances thermotolerance of photosystem II in tobacco plants.Planta , 225 (3), 719-733. doi:10.1007/s00425-006-0380-3

Zhang, R., Cruz, J. A., Kramer, D. M., Magallanes-Lundback, M. E., Dellapenna, D., \& Sharkey, T. D. (2009). Moderate heat stress reduces the $\mathrm{pH}$ component of the transthylakoid proton motive force in light-adapted, intact tobacco leaves. Plant, Cell \& Environment, 32 (11), 1538-1547. doi:10.1111/j.1365-3040.2009.02018.x

Zhang, R., Kramer, D. M., Cruz, J. A., Struck, K. R., \& Sharkey, T. D. (2011). The effects of moderately high temperature on zeaxanthin accumulation and decay. Photosynthesis Research , 108 (2-3), 171-181. doi:10.1007/s11120-011-9672-y

Zhang, R., \& Sharkey, T. D. (2009). Photosynthetic electron transport and proton flux under moderate heat stress. Photosynthesis Research , 100 (1), 29-43. doi:10.1007/s11120-009-9420-8

\section{FIGURE LEGENDS}

Figure 1:Temperature response of photosynthesis under different light intensities and in leaves of different maturity. A) photosynthetic efficiency $\left.\left(\mathrm{F}_{\mathrm{II}}\right), \mathrm{B}\right)$ light-induced thylakoid proton motive force ( pmf ) estimated by the ECSt parameter, C) ATP synthase activity $\left.\left(g_{\mathrm{H}}+\right), \mathrm{D}\right)$ non-photochemical quenching $(\mathrm{NPQ}), \mathrm{E})$ redox state of primary quinone acceptor $\left.\left(q_{\mathrm{L}}\right), \mathrm{F}\right) v_{\mathrm{H}}+/ \mathrm{LEF}$ and G) Relative change in the $v$ $\mathrm{H}+/$ LEF ratio. Data were normalized to values at $30{ }^{\circ} \mathrm{C}$ from Figure $1 \mathrm{~F}$. Leaf maturity is indicated by the line type: dashed line, mature leaves (ML, unifoliate leaves from 12 -day old seedlings); solid line, young leaves (YL, unifoliate leaves from 4-day old seedlings). The different colored lines represent measurements at low $\left(300 \mu \mathrm{mol} \mathrm{m} \mathrm{m}^{-2} \mathrm{~s}^{-1}\right)$ and high $\left(1000 \mu \mathrm{mol} \mathrm{m} \mathrm{m}^{-2} \mathrm{~s}^{-1}\right.$ and $\left.1500 \mu \mathrm{mol} \mathrm{m}^{-2} \mathrm{~s}^{-1}\right)$ light intensities as indicated in (A). Grey area represents recovery for at least $1 \mathrm{~h}$. Data are from cowpea genotype 'Yacine'. The temperatures reported are the air temperature in the chamber, which was changed every $2 \mathrm{~h}$, although, measurements were made after at least $1 \mathrm{~h}$ under each temperature. Data are means of 8-14 replicates from 2-3 independent experiments \pm 1 S.E.

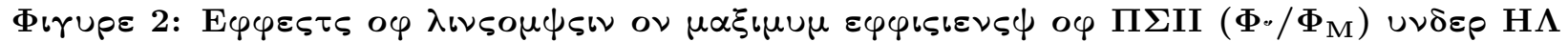
$\left(1500 \mu \mu о \lambda \mu^{-2} \varsigma^{-1}\right)$ op $\varsigma \circ \mu \beta \iota \varepsilon \delta \mathbf{H} \Lambda \alpha \nu \delta$ HT $\sigma \tau \rho \varepsilon \sigma \varsigma$. Starting from $1 \mathrm{~h}$ after lincomycin treatment, the kinetics of relative $\mathrm{F}_{\mathrm{V}} / \mathrm{F}_{\mathrm{M}}$ are shown for A) GT+HL and B) HT+HL treatments. Values are expressed relative to the initial $\mathrm{F}_{\mathrm{V}} / \mathrm{F}_{\mathrm{M}}$ values for each day. Leaves were syringe infiltrated with $0.2 \mathrm{~g} / \mathrm{L}$ lincomycin or deionized water. Dashed lines with hollow markers represent lincomycin treatment and solid lines with filled markers represent mock (water) infiltrated leaves. Line color indicates the temperature and light intensity treatment. Red $=\mathrm{HT}+\mathrm{HL}$ (high temperature + high-light), black $=\mathrm{GT}+\mathrm{HL}$ (growth temperature + high-light). For the GT $+\mathrm{HL}$ treatment, the temperature was kept constant $\left(30^{\circ} \mathrm{C}\right)$ throughout 
the $6 \mathrm{~h}$ period whereas the temperature for the HT+HL are indicated in the colored boxes above the data points. Data are from young cowpea leaves and the two genotypes (Yacine and 58-77) are used to show the differences in HL sensitivity which is abolished in HT + HL. The means of 4 replicates \pm 1 S.E are shown.

Figure 3: Temperature responses of $\mathrm{CO}_{2}$ assimilation-related processes in young leaves of cow-

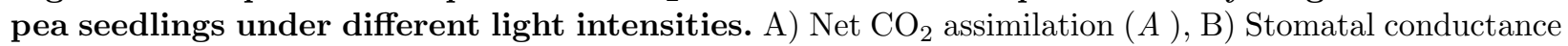
$\left(g_{\mathrm{s}}\right)$ and $\mathrm{C}$ ) Intercellular $\mathrm{CO}_{2}$ concentration $\left(\mathrm{C}_{\mathrm{i}}\right)$. The different colored lines represent measurements at low $\left(300 \mu \mathrm{mol} \mathrm{m} \mathrm{m}^{-2} \mathrm{~s}^{-1}\right)$ and high $\left(1000 \mu \mathrm{mol} \mathrm{m} \mathrm{m}^{-2} \mathrm{~s}^{-1}\right.$ and $\left.1500 \mu \mathrm{mol} \mathrm{m} \mathrm{m}^{-2} \mathrm{~s}^{-1}\right)$ light intensities as indicated in the legend in Figure 3B. Grey area represents recovery for at least $1 \mathrm{~h}$. Data are from young leaves (YL) of cowpea genotype 'Yacine'. The temperatures reported are the air temperature in the chamber, which was changed every $2 \mathrm{~h}$, although, measurements were made after at least $1 \mathrm{~h}$ under each temperature. Data are means \pm 1 S.E of at least 8 biological replicates from $2-3$ independent experiments.

Figure 4: Effect of temperature on velocity of rubisco for carboxylation $\left(v_{\mathrm{c}}\right)$ and oxygenation $\left(v_{\mathbf{o}}\right)$ and electron transport rate in cowpea.A-B) Temperature response of $v_{\mathrm{c}}$ and $v_{\mathrm{o}}$ in leaves of different maturity and under light intensities of A) $300 \mu \mathrm{mol}$ photons $\mathrm{m}^{-2} \mathrm{~s}^{-1}$ (low light - LL) and B) 1000 $\mu \mathrm{mol}$ photons $\mathrm{m}^{-2} \mathrm{~s}^{-1}$ (high-light - HL). C-D). The temperature response and light intensity dependence of electron transport rate measured by chlorophyll fluorescence (ETR) or calculated from gas exchange $\left(\mathrm{ETR}_{\mathrm{GE}}\right)$. The colors represent the different parameters as indicated in the y-axes of the leading (far left) figures. Closed symbols = young leaves (YL), open symbols = mature leaves (ML). LL Data are means of 6-8 replicates with error bars being \pm 1 S.E. Assumptions used in calculating $v_{\mathrm{c}}$ and $v_{\mathrm{o}}$ are outlined in the Materials and Methods.

Figure 5: Comparison of responses of net $\mathrm{CO}_{2}$ assimilation $(A)$ and ETR/4 to internal $\mathrm{CO}_{2}$ concentration $\left(C_{\mathrm{i}}\right)$ in different light intensities, $\mathrm{O}_{2}$ levels and temperature in young cowpea leaves. Response of $\mathrm{A}$ and $\mathrm{ETR} / 4$ against $C_{\mathrm{i}}$ under low light $\left(300 \mu \mathrm{mol}\right.$ photons $\left.\mathrm{m}^{-2} \mathrm{~s}^{-1}\right)$ at $\left.\mathrm{A}-\mathrm{B}\right) 30$ ${ }^{\circ} \mathrm{C}$ and $\left.\mathrm{C}-\mathrm{D}\right) 45^{\circ} \mathrm{C}$ respectively. Corresponding measurements at high light $\left(1000 \mu \mathrm{mol}\right.$ photons $\left.\mathrm{m}^{-2} \mathrm{~s}^{-1}\right)$ are shown in E-F and G-H respectively. The circled points represent the first measurements made under ambient $\mathrm{CO}_{2}$. Data are means \pm 1 S.E of 3-10 biological replicates from 1-3 independent experiments.

Figure 6: HT treated plants exhibit less photo-inhibitory quenching under prolonged dynamic and high light conditions. Changes in A) $\mathrm{F}_{\mathrm{II}}$, B) Non- photochemical quenching $\left(\mathrm{NPQ}_{(\mathrm{T})}\right)$, C) Photoinhibitory quenching $\left(q_{\mathrm{I}(\mathrm{T})}\right)$ and D) the rapidly reversible (photoprotective) quenching $\left(q_{\mathrm{E}(\mathrm{T})}\right)$ during a 4-day experiment with corresponding temperature and light intensity ( $\mathrm{PAR}=$ photosynthetically active radiation $-\mu \mathrm{mol}$ photons $\mathrm{m}^{-2} \mathrm{~s}^{-1}$ ) changes indicated in the top panel of Figure $6 \mathrm{~A}$. The color of the lines corresponds to the colors of the temperature. Dashed line $=58-77$, solid lines=Yacine. The suffix after the genotype names indicates the temperature treatment. Data are means of 5-8 replicates from 1-2 independent experiments. Measurements were made at $20 \mathrm{~min}$ intervals on days 1 and 4 and at $1 \mathrm{~h}$ intervals on days 2 and 3 using the CCD (charge coupled device) cameras in the DEPI (Dynamic Environment Photosynthesis Imager) chamber (Cruz et al., 2016).

\section{Hosted file}

Photoprotection_Figures F1.docx available at https://authorea.com/users/344964/articles/ 471320-the-roles-of-photorespiration-and-alternative-electron-acceptors-in-the-

responses-of-photosynthesis-to-elevated-temperatures-in-cowpea 